visits. Family work is generally necessary, including at times the employment of contracts to manage boundary issues in over-involved families. Regular input from outside agencies for staff and patients, through the course of admission, is encouraged. Training and staff support are important. Strong links with the supported accommodation officer and the community rehabilitation team have proved helpful in finding appropriate placement and ongoing support after residential rehabilitation.

\section{Acknowledgements}

We thank the Barnwood Trust, which contributed to the cost of data analysis; Heather Priestley for her help with data collection; and Julie Bundy for her work on producing the manuscript.

\section{References}

DEPARTMENT OF HEALTH (1996) Residential Needs for Severely Disabled Psychiatric Pattents: The Case for Hospital Hostels. London: Department of Health

HAWTHORNE, W. B., FALS-STEWARD, W. \& COHR, J. B. (1994) A treatment outcome study of community-based residential care. Hospital and Community Psychiatry. 46. 152-155.

LELUOTT, P. (1996) Meeting the accommodation needs of the most severely mentally ill. Joumal of Interprofessional Care, 10, 241-247.
NHS EXrcuTIVE (1994) 24-Hour Nursed Care for People with Severe and Enduring Mental Illness. Leeds: NHS Executtve.

REID, Y. \& GARRETY, P. (1996) A hostel-ward for new long stay patients: Sixteen years progress. Journal of Mental Health, 5, 77-89.

SHEPHERD, G. (1991) Psychiatric rehabilitation for the 1990s. In Theory and Practice of Psychlatic Rehabilitation (eds F. N. Watts \& D. H. Bennett). Chichester: Wiley.

-. KInG, C. \& Fowher, D. (1994) Outcomes in hospice hostels. Psychiatric Bulletin, 18, 609-612.

SiMPSON, S. \& MiDDLETON, N. (1994) Fast stream psychlatric rehabilitation after recent hospital closure. Psychiatric Bulletin, 18, 613-614.

WorLd HEAlth Organization (1978) Mental Disorders: Glossary and Guide to thetr Classification in Accordance with the Ninth Revision of the International Classification of Diseases (ICD-9). Geneva: WHO.

WYKEs, T. \& WING. J. K. (1982) "New" long-stay patients: An evaluative study of a "ward in a house". Monograph Supplement 2, Psychological Medicine. Cambridge: Cambridge University Press.

Young, R. (1991) Residential Needs of Severely Disabled Psychlatric Patients - the Case for Hospital Hostels. London: HMSO.

*Rob Macpherson, Consultant in Rehabilitation/ General Psychiatry, Wotton Lawn, Horton Road, Gloucester GL1 3LW; and Julian Butler, Registered Mental Nurse and Manager, The Vron Rehabilitation Hostel, Gloucester

*Correspondence

\title{
Electroconvulsive therapy in Wales
}

\author{
Richard Duffett, Drew Ridley Siegert and Paul Lelliott
}

\begin{abstract}
Aims and mothod The use of electroconvulsive therapy (ECI) was surveyed over the first six months of 1996 in Wales. Data on the indications for ECT and clinical outcome were collected in the first three months.

Results The computed annual rate was 22 patients treated with ECT per 100000 population. Women constituted $71 \%$ of those recelving ECT (236/321). Elghty-three per cent had an affective disorder, and $80 \%$ had falled to respond to previous treatments. Only $33 \%$ of patients had been prescribed more than one class of antidepressant, and only $25 \%$ had recelved augmentation with lithium or an alternative drug before being given ECT.

Clinical implications ECT is mostly used after a fallure of patients to respond adequately to a course of antidepressants.
\end{abstract}

Between 1990 and 1993 (data were last collected in Wales in 1993), the number of patients reported to be receiving electroconvulstve therapy (ECT) in Wales fell from by 26\% from 39 to 29 per 100000 population (Welsh Office, 1994). A number of factors may account for this:

(a) Improvements in pharmacotherapy with the introduction of effective antidepressants with fewer side-effects and the increased use of lithium as an adjunct. The treatment of resistant depression has probably also become more systematic with the introduction of treatment protocols.

(b) Stigma and adverse publicity may have made patients more reluctant to accept 
ECT and psychiatrists less ready to prescribe it.

(c) Incomplete recording of the number of patients receiving ECT.

Practice between individual services and health authorities practice has varied widely. In 1991 there was a nearly five-fold variation in the use of ECT between Welsh health authorities, with the annual number of treatment applications ranging from 113 to 541 per 100000 population and the number of patients treated from 16 to 71 per 100000 population.

The practice of ECT in Wales reflects that elsewhere in the UK. In England in 1990 the rate of administration of ECT per head of population varied over 10-fold between individual services (Pippard, 1992) and three-fold between regions (Government Statistical Office, 1992). Between 1985 and 1991 (the last time national figures were collected in England) the number of treatment applications in England fell by $24 \%$ (from 291 treatments per 100000 population in 1985 to 220 per 100000 population in 1991 Government Statistical Office, 1992).

These findings must be treated cautiously because of concern about the accuracy of centrally collected data. In England a previous audit by the Royal College of Psychiatrists Research Unit (CRU) found that some clinics had reported only $39 \%$ of the applications administered (Pippard, 1992).

The study reported here aimed to gain a complete and accurate picture of the pattern of use of ECT in Wales during the first six months of 1996. More detailed information was collected from consultant psychiatrists responsible for patients who started ECT during the first three months of 1996.

\section{The study}

All 17 NHS ECT clinics in the five health authorities of Wales (population 2910 000) were identified by phoning mental health trusts. All were visited by the first author as part of the CRU's third audit of ECT (Duffett \& Lelliott, 1998). Data were collected prospectively on all patients commencing ECT during the first six months of 1996. To ensure patient confidentiality, information was first collected locally (usually by the nurse responsible for running the clinic) about age and gender of patients and about the number of treatment applications they received before anonymous returns were made to CRU.

In addition, a questionnaire was sent by local data coordinators to the consultant psychiatrist of every patient commencing treatment in the first three months of 1996. This enquired about the patient's diagnosis, the indication for ECT, other treatment given during the index episode of illness, status under the Mental Health Act 1983 and previous admissions to hospital. Clinicians also rated their impression of the change in the patient's condition following ECT using the Clinical Global Impression Scale of Change (CGI; Guy, 1976). Mid-1996 population estimates were obtained from the Welsh Office (Government Statistical Office, personal communication, 1996). Results were analysed using the computer statistical package SPSS for Windows 95.

\section{Results}

Use of ECT during the first six months of 1996

We identified 321 patients, 92 men (29\%) and 239 women $(71 \%)$ as having commenced a course of ECT during this period: this represents an annual rate of 22 patients per 100000 population. The mean age of men and women was 55.5 and 56.9 years respectively. The number of courses of ECT is shown as a computed annual rate per age and gender specific population in Figure 1. When adjusting for representation in the general population of Wales those over age 65 years were 2.25 times more likely to be prescribed ECT than those between the ages 20 and 64 (24 v. 58 per $100000)$. The number of patients treated in each clinic with ECT ranged from 1-61.

Table 1 shows the rate of ECT use in the five Welsh health authorities during the study period. The highest prescribing health authority (Dyfed Powys) treated 1.6 times as many people per 100000 population as the lowest (North Wales) - this difference was significant $\left(\chi^{2}\right.$. $P<0.01)$. Variation was greater in the rate of treatment for people aged between 20-64 years (range 13.3-26.8 per 100000 population) than

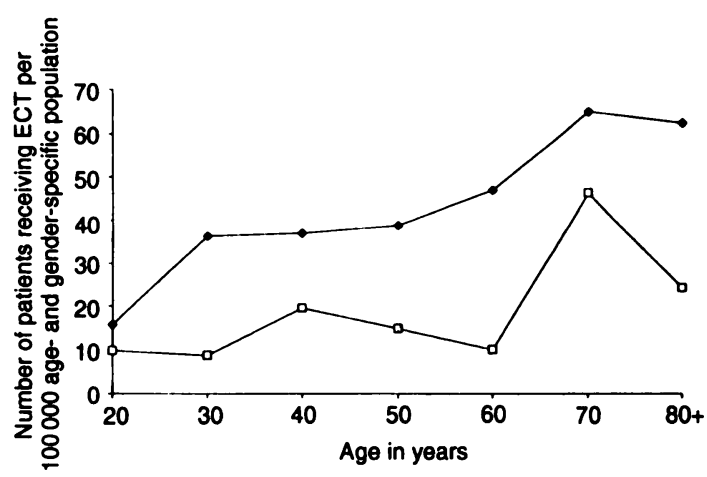

Fig. 1. Computed annual number of electroconvulsive therapy (ECD) courses per 100000 age and gender-specific population. ^-, women; ㄴ. men. 
Table 1. Electroconvulsive therapy (ECD) treatment in first six months of 1996 in the five Welsh health authorities

\begin{tabular}{|c|c|c|c|c|c|c|}
\hline Health outhority & North Woles & Dyted Powys & Morgannwg & Bro Tof & Gwent & Total in Wales \\
\hline $\begin{array}{l}\text { Number of male patients starting } \\
\text { treatment }\end{array}$ & 13 & 24 & 12 & 27 & 16 & 92 \\
\hline $\begin{array}{l}\text { Number of female patients } \\
\text { starting treatment }\end{array}$ & 42 & 41 & 47 & 63 & 36 & 229 \\
\hline Total patients treated & 55 & 65 & 59 & 90 & 52 & 321 \\
\hline Population & 656900 & 476700 & 499900 & 752500 & 556200 & 2921100 \\
\hline $\begin{array}{l}\text { Patients prescribed ECT per } \\
100000 / \text { year }^{\prime}\end{array}$ & 0.168 & 0.273 & 0.236 & 0.246 & 0.187 & $\begin{array}{ll}7 & 0.220\end{array}$ \\
\hline $\begin{array}{l}\text { Estimated ECT applications per } \\
100000 \text { year }\end{array}$ & 10.3 & 20.2 & 15.5 & 18.8 & 11.4 & 15.2 \\
\hline
\end{tabular}

1. Adjusted for missing data.

for those aged 65 or over (range 45.3-63.2 per 100000 population).

The duration of the course of ECT was known for 291 patients $(91 \%)$. The mean number of treatments per completed course was 6.75 (median 6, range 1-8). Patients were most likely to receive an even number of treatments $161 \%$. $\left.\chi^{2}, P<0.001\right)$. The mean number of treatments per course ranged from 6-7.6 between health authorities; this difference was significant ( $t$-test, $P<0.01)$. There were however no differences in the mean number of treatments between the genders or in those older or younger than 65 years old.

Data on treatment duration were more complete for patients commencing ECT in the first quarter of 1996 than the second $(99 \% v$. 92\% complete) due to a failure to record the total number of treatments for some patients still receiving ECT in July 1996 . This resulted in the mean number of treatments per course in the second quarter being shorter than the first (6.4 $v$. 7.3. $P<0.02$ ). When the total number of treatments applications administered in Wales in 1996 were extrapolated from the mean number of treatments given in the first quarter of 1996, it was calculated that about 4668 treatment applications would have been administered to 642 patients annually.

\section{Indications for ECT during the first three months of 1996}

Complete returns were received for 132 of the 161 patients who commenced ECT in the first quarter of $1996(82 \%)$. The majority of nonreturns (20 of the 29) were from two sites. Patients for whom there were missing data did not differ significantly in terms of their age or gender from the rest of the sample.

Table 2 summarises the diagnosis, Mental Health Act status, previous history, other treatment during the index illness and indications for ECT of these patients. A failure to respond to drug therapy was the most common reason for
Table 2. Characteristics of patients commenced on electroconvulsive therapy (ECD) in Wales during the first three months of 1996

\begin{tabular}{|c|c|c|c|}
\hline & $\begin{array}{l}\text { Moles } \\
(n=37)\end{array}$ & $\begin{array}{l}\text { Females } \\
(n=89)\end{array}$ & $\begin{array}{l}\text { Total' (\%) } \\
(n=132)\end{array}$ \\
\hline \multicolumn{4}{|l|}{ Diagnosis } \\
\hline Depression & 29 & 69 & $102(82)$ \\
\hline Mania & 1 & 0 & $1(1)$ \\
\hline Mixed affective state & 2 & 2 & $6(5)$ \\
\hline Schizoaffectice disorder & 1 & 8 & $9(7)$ \\
\hline Schizophrenia & 2 & 4 & $6(5)$ \\
\hline Puerperal psychosis & 0 & 1 & $1(1)$ \\
\hline \multicolumn{4}{|l|}{ Indication } \\
\hline Life-saving procedure & 6 & 8 & 17 (13) \\
\hline Failure to respond & 29 & 75 & $106(80)$ \\
\hline Patients choice & 2 & 4 & $7(5)$ \\
\hline \multicolumn{4}{|l|}{ Past history } \\
\hline Previously hospltallised & 24 & 66 & $95(72)$ \\
\hline Previously ECT & 15 & 52 & $72(55)$ \\
\hline \multicolumn{4}{|l|}{ During current episode } \\
\hline $\begin{array}{l}\text { Detained under Mental } \\
\text { Health Act }\end{array}$ & 6 & 17 & $26(20)$ \\
\hline $\begin{array}{l}\text { Treated under Mental } \\
\text { Health Act }\end{array}$ & 1 & 8 & $12(9)$ \\
\hline Recelved ECT & 5 & 15 & $24(18)$ \\
\hline Tricyclic antidepressant & 24 & 53 & $82(62)$ \\
\hline $\begin{array}{l}\text { Selective serotonin } \\
\text { reuptake inhibitor }\end{array}$ & 19 & 52 & $75(57)$ \\
\hline Monoamine oxidase & 3 & 12 & $15(11)$ \\
\hline $\begin{array}{l}\text { inhibltor or reversible } \\
\text { inhibitor of monoamine } \\
\text { oxidase A (RIMA) }\end{array}$ & & & \\
\hline Any antidepressant & 33 & 81 & $119(90)$ \\
\hline $\begin{array}{l}\text { More than one } \\
\text { antidepressant }\end{array}$ & 11 & 30 & $41(33)$ \\
\hline \multicolumn{4}{|l|}{ Augmentation strategies } \\
\hline Uthium & 9 & 20 & $31(23)$ \\
\hline Anticonvulsant & 1 & 8 & $9(7)$ \\
\hline $\mathrm{T} 3$ or $\mathrm{T} 4$ & 0 & 2 & $2(2)$ \\
\hline L-Tryptophan & 1 & 5 & $7(5)$ \\
\hline $\begin{array}{l}\text { Any augmentation } \\
\text { strategy }\end{array}$ & 9 & 22 & $33(25)$ \\
\hline \multicolumn{4}{|l|}{ Other psychotropic medication } \\
\hline Antipsychotic & 16 & 43 & $63(48)$ \\
\hline Benzodiazepine & 6 & 22 & $29(22)$ \\
\hline
\end{tabular}

1. Data were missing on the gender of six patients. 
starting ECT ( $80 \%$ of the sample, $n=106)$ Consistent with this only four patients with depressive illness had not received an antidepressant prior to commencing ECT. The majority of patients were commenced on ECT as in-patients, with only $21(16 \%)$ commencing treatment as out-patients. Although about onefifth of patients were detained under the Mental Health Act only $9 \%(n=12)$ were given ECT against their consent (under Sections 58 or 62 of the Mental Health Act 1983). The indications (more than one might apply) for treatment in those starting ECT under compulsion were as a life saving procedure (eight); failure to respond to alternative treatments (seven); and failure to tolerate antidepressants (one).

Fifty-nine per cent $(n=78)$ of patients were rated as much or very much improved, a further $31 \%(n=41)$ as improved and only two as worse following their course of ECT. All 12 patients who were commenced on ECT against their consent were rated as improved.

\section{Discussion}

The study gives an almost complete picture of the use of ECT in Wales during the first half of 1996. As personnel involved in the administration of ECT collected data on the use and all clinics were visited by R.D. during data collection period and accuracy is likely to be high. The survey design was appropriate to examine rates of ECT use and variation in rates between health authorities and the age, gender and Mental Health Act status of patients. The design was not ideal to describe patients' clinical details because data were collected by a large number of psychiatrists and not using rigorous research methods. Even with these reservations, data on diagnosis, previous treatment, indications for use and outcomes are presented because they complement the picture by adding a clinical element.

The age and gender distribution of patients was very similar to those found in an audit of ECT practice in Great Britain conducted in 1980 (Pippard \& Ellam, 1981) and other studies (O'Leary \& Lee, 1996; Trezise \& Conlon, 1997). Likewise the mean number of treatments per course (6.75) was very similar to those of the 1980 survey $(6.55)$.

The data on rates of use are likely to be more accurate than those derived from central returns, and for this reason comparisons need to be made cautiously. With this caveat, the findings of this study suggest that, since 1990 . the annual number of applications of ECT in Wales has fallen by $30 \%$ and of patients treated by $44 \%$. Also variation between health authorities in rates of use has reduced (from 5-1.6-fold) although much larger variations occur between individual services.

If this fall in the rate of ECT is real it might be in part due to more extensive use of pharmacotherapy before ECT is prescribed. A survey of prescribing practice conducted in the 1980 audit (Pippard \& Ellam, 1981) reported that before ECT was given, $71 \%$ of patients with depression had had a trial of antidepressants (this compares with $96 \%$ in this study), and only $8 \%$ had commenced a lithium or another augmentation strategy (25\% in this study). Fallure to respond adequately to an oral antidepressant was the reported indication for ECT in 50\% of patients in 1980 compared with $80 \%$ in this study.

Despite this change, the 1996 survey does suggest that pharmacological treatments are not used exhaustively before ECT is given as only $33 \%$ of patients had been prescribed more than one class of antidepressant during the index illness. ECT in Wales is used principally as a treatment for affective disorders, consistent with guidelines produced by The Royal College of Psychiatrists (1995).

The survey does not indicate what other factors might have influenced the decision to use ECT, such as a wish to bring about a rapid improvement in mood either to relieve suffering or to enable earlier discharge.

\section{Acknowledgements}

The authors wish to thank the psychiatrists and clinical staff who assisted in providing these data. The project was funded by a grant from the Welsh Office.

\section{References}

DUFFETT, R. \& LELUOT, P. (1998) Auditing electroconvulstve therapy. The third cycle. British Journal of Psychiatry. 172, 401-405.

GOVERNMENT STATISTICAL OFFICE (1992) Electroconurulstue Therapy: England-Year Ending 31 March 1991. London: Government Statistical Office.

GuY, W. (1976) ECDEU Assessment Manual for Psychopharmacology. Revised DHEW Pub (ADM). Rockville, MD: National Institute of Mental Health.

O'LeARY D. A. \& LEe, A. S. (1996) Seven-year prognosis in depression. Mortality and readmission risk in the Nottingham ECT cohort. British Joumal of Psychiatry. 169, 423-429.

PIPPARD, J. (1992) Audit of electroconvulsive treatment in two National Health Service regions. British Journal of Psychiatry. 160, 621-637.

- \& EuAM, L. (1981) Electroconurulstue treatment in Great Britain, 1980. London: Gaskell.

ROYAL COUEGE OF PSYCHIATRISTS (1995) The ECT Handbook: The Second Report of the Royal College of Psychiatrists Special Committee on ECT. Council Report CR39. London: Gaskell.

TREZASE. K. \& CONLON, B. (1997) Effects of changes in the practice of electroconvulstve therapy over a two-year period. Psychiatric Bulletin, 21, 10-12. 
WelSH OFmCE (1994) Mental Health Statistics for Wales. London: HMSO.

*Richard Duffett, Clinical Research Fellow. The Royal College of Psychiatrists Research Unit, London and Specialist Registrar Trainee, Tower Hamlets Healthcare NHS Trust, St Clement's Hospital, 2A Bow Road, London E3 4LL; Drew
Ridley Siegert, Consultant Old Age Psychiatrist, Whitchurch Hospital, Cardiff; and Paul Lelliott, Director. The Royal College of Psychiatrists Research Unit, London

*Correspondence

\title{
Treatment of the mentally ill in the Federal Republic of Germany
}

\section{Sectioning practice, legal framework, medical practice and key differences between Germany and the UK}

\author{
Hanns Rüdiger Röttgers and Peter Lepping
}

\begin{abstract}
Aims and method The legal provisions concerning the admission to hospital, holding powers and compulsory treatment of the mentally III in Germany are illustrated. The essential legal concepts are compared to the stuation in Great Britain.

Results Whereas British law gives key powers to multtprofessional decision-making and relatives, German law requests formal court decisions even in routine cases. This reflects a different understanding of individual rights and their protection. German mental health law is mottvated by the experiences of the totalitarian national sociallst regime. It tries to protect patients' rights by restricting physicians', hospltals' and family members' influence. British law, on the other hand, assumes that experts as well as family members act benevolently in the patient's interest, prefers less formal mechanisms and expresses more trust in professional ethics.

Conclusion Further research is desirable to analyse the situations in other countries and to determine which of these approaches is the most adequate from the point of view of the mentally ill. This is even more important in view of further European integration which will undoubtedly touch these questions and accelerate a convergence in medico-legal issues.
\end{abstract}

European integration will not only lead to an integration of economic markets, but also to more similar standards of the service sector, professions and jurisdiction. Whereas the medical and scientific standards in Great Britain and Germany are comparable, fundamental differ- ences exist in medico-legal concepts and the psychiatric practice as far as sectioning, forced treatment and guardianship issues are concerned. This has recently been highlighted by several High Court decisions.

\section{Sectioning law and Guardianship law in Germany}

In the Federal Republic of Germany there is a separation between public and civil law regarding Sectioning and Guardianship.

Public law is the domain of the 16 Federal States, each of which has a different sectioning law (Unterbringungsgesetz). Its function is to avert dangers to public order and security relating to mentally ill persons. Public law does not care about individual welfare or health. Guardianship law (Betreuungsgesetz) as part of the civil law on the other hand is Identical in all 16 Federal States.

Its function is to grant the proper personal. medical and economic care for those people not able to do so themselves due to handicap or illness. A guardian appointed by the local court then takes care of such persons. The guardian's rights have to be specified according to the circumstances of the individual case. Those rights can for example comprise "financial issues with the exception of everyday transactions up to DM100 per week" or "psychiatric treatment 